\title{
Characteristics of a broad lytic spectrum endolysin from phage BtCS33 of Bacillus thuringiensis
}

Yihui Yuan, Qin Peng and Meiying Gao*

\begin{abstract}
Background: Endolysins produced by bacteriophages lyse bacteria, and are thus considered a novel type of antimicrobial agent. Several endolysins from Bacillus phages or prophages have previously been characterized and used to target Bacillus strains that cause disease in animals and humans. B. thuringiensis phage BtCS33 is a Siphoviridae family phage and its genome has been sequenced and analyzed. In the BtCS33 genome, orf18 was found to encode an endolysin protein (PlyBt33).

Results: Bioinformatic analyses showed that endolysin PlyBt33 was composed of two functional domains, the $\mathrm{N}$-terminal catalytic domain and the C-terminal cell wall binding domain. In this study, the entire endolysin PlyBt33, and both the $\mathrm{N}$ - and C-termini,were expressed in Escherichia coli and then purified. The lytic activities of PlyBt33 and its $\mathrm{N}$-terminus were tested on bacteria. Both regions exhibited lytic activity, although PlyBt33 showed a higher lytic activity than the N-terminus. PlyBt33 exhibited activity against all Bacillus strains tested from five different species, but was not active against Gram-negative bacteria. Optimal conditions for PlyBt33 reactivity were pH 9.0 and $50^{\circ} \mathrm{C}$. PlyBt33 showed high thermostability, with $40 \%$ of initial activity remaining following $1 \mathrm{~h}$ of treatment at $60^{\circ} \mathrm{C}$. The C-terminus of PlyBt33 bound to B. thuringiensis strain HD-73 and Bacillus subtilis strain 168 . This cell wall binding domain might be novel, as its amino acid sequence showed little similarity to previously reported endolysins.
\end{abstract}

Conclusions: PlyBt33 showed potential as a novel antimicrobial agent at a relatively high temperature and had a broad lytic spectrum within the Bacillus genus. The C-terminus of PlyBt33 might be a novel kind of cell wall binding domain.

Keywords: Bacillus thuringinesis, Bacteriophage, Endolysin, N-acetylmuramoyl-L-alanine amidase

\section{Background}

Endolysins are enzymes produced by bacteriophages (phages) at the end of their life cycles to lyse the cell walls of host cells and release mature progeny phage particles [1,2]. Most endolysins require a second phage protein, holin, to create pores in the cytomembrane and enable them to pass through to reach their substrate, a cell wall peptidoglycan $[3,4]$. Because of their potential as novel antibacterial agents, the characteristics of several endolysins have previously been studied [5-10].

\footnotetext{
* Correspondence: mygao@wh.iov.cn

Key Laboratory of Agricultural and Environmental Microbiology, Wuhan Institute of Virology, Chinese Academy of Sciences, Wuhan 430071, P.R. China
}

\section{Biomed Central

(c) 2012 Yuan et al.; licensee BioMed Central Ltd. This is an Open Access article distributed under the terms of the Creative Commons Attribution License (http://creativecommons.org/licenses/by/2.0), which permits unrestricted use, distribution, and reproduction in any medium, provided the original work is properly cited.
Endolysins of phages isolated from Gram-positive bacteria typically contain two functional domains, the $\mathrm{N}$-terminal catalytic domain and the $\mathrm{C}$-terminal cell wall binding domain [1]. The catalytic domain belongs to one of the four families of peptidoglycan hydrolases, which are classified according to catalytic site-specificity: $\mathrm{N}$-acetylglucosaminidases, $\mathrm{N}$-acetylmuramidases (lysozymes), $\quad N$-acetylmuramoyl-L-alanine amidases, and endopeptidases $[1,11]$. By contrast, the cell wall binding domain is divergent and can distinguish discrete cell wall epitopes. Usually, one cell wall binding domain determines the endolysin strain specificity $[11,12]$; however, there are sometimes more than one $[7,13,14]$ or even no cell wall binding domains $[15,16]$. The endolysin C-terminus nevertheless sometimes appears to be 
essential for catalytic activity, as several reports showed that the enzymatic activity is abolished after removal of the C-terminus $[17,18]$.

Bacillus thuringiensis belongs to the Bacillus cereus group, which includes two very closely related species: B. cereus and Bacillus anthracis [19]. B. thuringiensis is an insect pathogen that forms an insecticidal crystal protein during sporulation [20]. B. anthracis is the anthrax pathogen, while $B$. cereus is a food contaminant [19]. Because of the multidrug resistance of $B$. anthracis [21,22], several of its phage or prophage endolysins have been expressed, purified, and characterized. There have also been some attempts to use these endolysins to cure the disease caused by $B$. anthracis $[8,9,11,17,18,23]$. Practical applications of endolysins were enabled by studies on functional domain composition, optimal reaction conditions, and species- or strain-specificity. For example, combining the catalytic domain of one endolysin with the cell wall binding domain of another changed the specificity or activity [24].

Until now, only two bacterial cell wall hydrolases from B. thuringiensis phage GIL01 have been reported [25], and little is known about their functional domain composition. The lytic activity of one of these hydrolases was

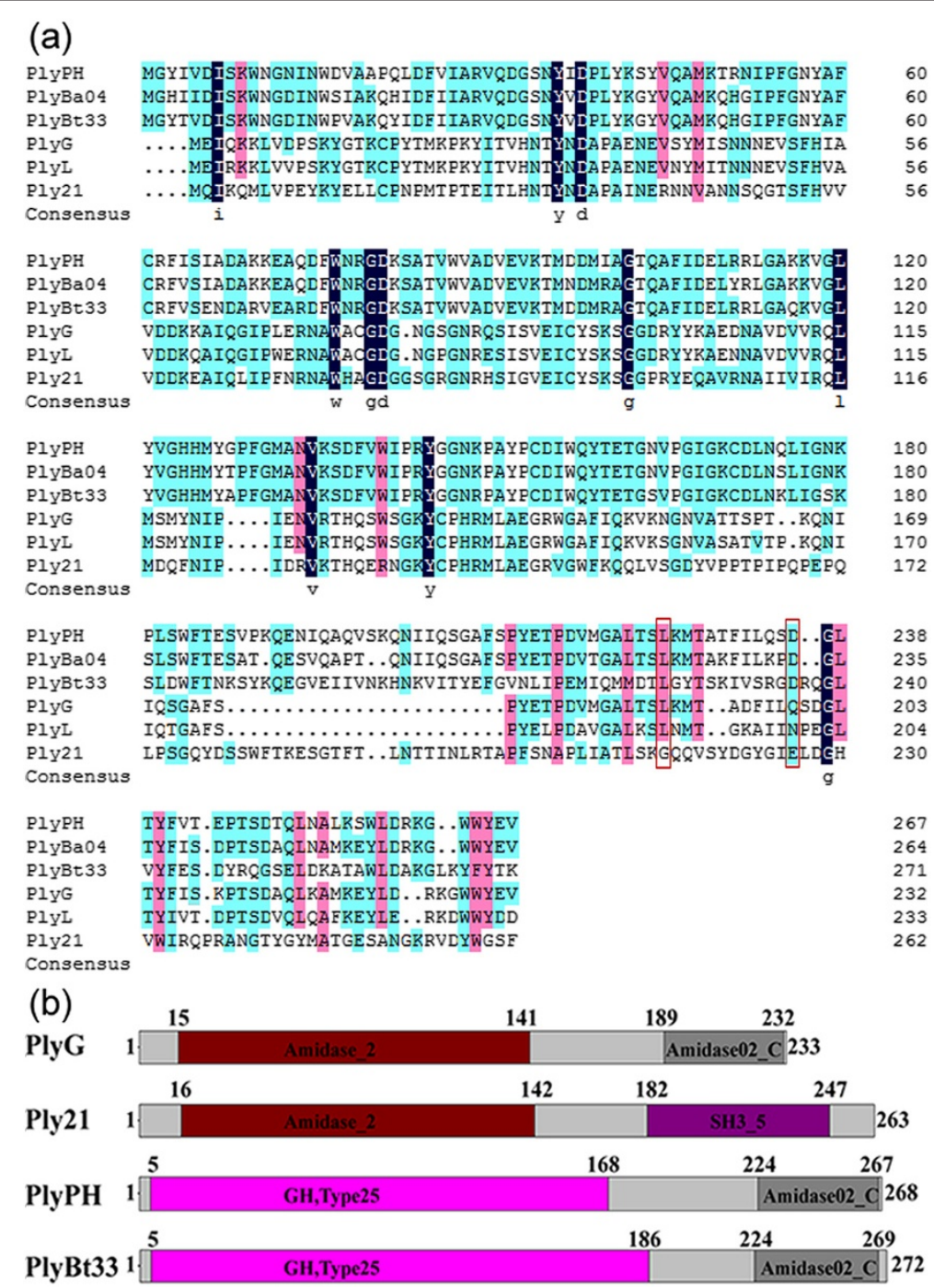

Figure 1 Amino acid sequence alignment and structural composition of the studied Bacillus endolysins. (a) Alignment of the amino acid sequences of PlyBt33 with other bacteriophage endolysins. PlyPH, PlyBa04, and PlyL were the putative B. anthracis prophage endolysins [9,16,22]; PlyG was the endolysin from B. anthracis phage Gamma [17,28]; Ply21 was the endolysin from B. cereus phage TP21 [9,29]. Residues critical for the cell wall binding activity of PlyG to $B$. anthracis [30] and the corresponding residues in the other endolysins were boxed in red. (b) Schematic representation of PlyBt33 and other Bacillus. sp. endolysins. Amidase_2 and GH-25 represented the catalytic region of each endolysin; Amidase02_C and SH3_5 represented the cell wall binding region of each endolysin. The numbers above the rectangles corresponded to amino acid residue positions. 
limited to $B$. thuringiensis israelensis, while the other exhibited a broader cleavage spectrum in lysing two other Gram-positive species, B. subtilis and Micrococcus lysodeikticus.

Phage BtCS33 is a Siphoviridae family member that was isolated from B. thuringiensis kurstaki strain CS-33 [26]. The BtCS33 genome has been sequenced and a potential endolysin gene, orf18, was identified using bioinformatics. The gene product was named PlyBt33. In this study, we analyzed the functional domain composition of PlyBt33 using bioinformatics, and then demonstrated its biological activity after separately expressing the catalytic and cell wall binding domains in Escherichia coli. PlyBt33 showed a broad lytic spectrum against the tested Bacillus strains. Additionally, its cell wall binding domain exhibited low amino acid sequence similarity to previously reported domains.

\section{Results}

Identification and domain composition of endolysin from phage BtCS33

Position-specific iterated BLAST (PSI-BLAST) analysis of the phage BtCS33 genome identified orf 18 as the gene encoding the endolysin PlyBt33. Amino acid sequence alignment of PlyBt33 with several endolysins from Bacillus phages or prophages (Figure 1a) revealed high similarity to $\mathrm{PlyPH}$ [9] and PlyBa04 [23] (about 67\% and 71\%, respectively), but low similarity to PlyG [18], PlyL [17], and Ply21 [27] (less than 15\%).

Pfam and CDD analysis showed that PlyBt33 was composed of two functional domains (Figure 1b), the Nterminal catalytic domain (amino acid residues 5-186) and the C-terminal cell wall binding domain (amino acid residues 224-269). Figure 1b showed the Pfam analysis of four endolysins from Bacillus phages, and indicated that the N-terminus of PlyBt33 was a GH25 family hydrolase domain, while the C-terminus was an amidase02_C domain. PlyBt33 exhibited the same domain composition as PlyPH, but differed from PlyG and Ply21. According to homology-based endolysin classification [1], PlyBt33 is a putative member of the $\mathrm{N}$-acetylmuramoyl-L-alanine amidases.

\section{Expression and purification of endolysin}

To determine the function of the entire PlyBt33 protein, the $\mathrm{N}$-terminal region (PlyBt33-N, amino acids 1-186), and the $\mathrm{C}$-terminus combined with the internal region (PlyBt33-IC, amino acids 187-272) (Figure 2a), we constructed three recombinant strains and induced protein expression with isopropyl- $\beta$-D-thio-galactoside (IPTG). Sodium dodecyl sulfate polyacrylamide gel electrophoresis (SDS-PAGE) analysis showed that the three observed molecular weights coincided with their theoretical weights of $31 \mathrm{kDa}, 24 \mathrm{kDa}$, and $11 \mathrm{kDa}$, respectively. SDS-PAGE analysis also showed that the purity of each protein following Ni-NTA purification exceeded 90\% (Figure 2b).

\section{Lytic activity of PlyBt33}

The relationship between different concentrations of PlyBt33 and their corresponding lytic activities was tested. Figure 3 showed a linear relationship from $0.5 \mu \mathrm{M}$ to $4 \mu \mathrm{M}$. For further assays, we used a final concentration of $2 \mu \mathrm{M}$ as this concentration lies within the linear activity range of PlyBt33. The lytic activities of PlyBt33-N and PlyBt33-IC were investigated to determine the active region of PlyBt33. The results revealed that PlyBt33-N but not PlyBt33-IC lysed B. thuringiensis strain HD-73

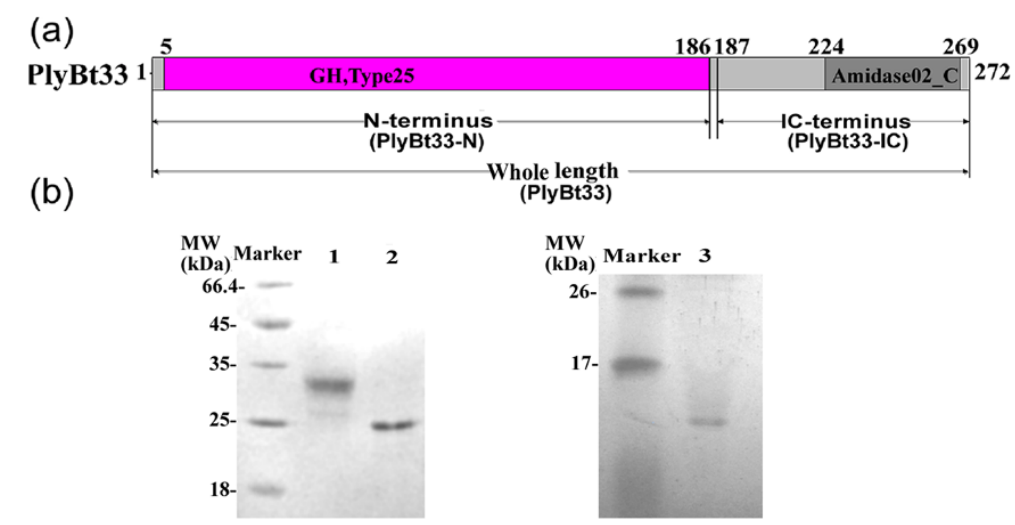

Figure 2 Schematic diagram and SDS-PAGE analysis of expressed PlyBt33 and its functional domains. (a) Schematic diagram of expressed PlyBt33 (full length), PlyBt33-N (N-terminal), and PlyBt33-IC (IC-terminal) proteins. The numbers above the rectangle correspond to amino acid residues. (b) SDS-PAGE analysis of expressed and purified PlyBt33, PlyBt33-N, and PlyBt33-IC proteins. Marker, molecular mass marker; lane 1, Ni-NTA column-purified PlyBt33 from E. coli supernatant following ultrasonication; lane 2, Ni-NTA column-purified PlyBt33-N from E. coli supernatant following ultrasonication; lane 3, Ni-NTA column-purified PlyBt33-IC from E. coli supernatant following ultrasonication. PlyBt33, PlyBt33-N, and PlyBt33-IC bands appeared at $33 \mathrm{kDa}, 24 \mathrm{kDa}$, and $11 \mathrm{kDa}$, respectively. 




Figure 3 Relationship between PlyBt33 concentration and lytic activity. Lytic activities of PlyBt33 on viable cells of $B$. thuringiensis strain HD-73 with different PlyBt33 concentrations were tested. The initial $\mathrm{OD}_{600}$ of the strain suspension was 0.8 and the test was carried out at $37^{\circ} \mathrm{C}$ in $20 \mathrm{mM}$ Tris- $\mathrm{HCl}(\mathrm{pH} \mathrm{8.0)}$. The decrease of $\mathrm{OD}_{600}(\%)=(1-$ the absorbance of the bacterial suspension at the end of each treatment / the absorbance at the beginning of each treatment) $\times 100 \%$. The assay was carried out in triplicate and the mean values were used.

(Figure 4a-d). This suggested that the active region of PlyBt33 was the N-terminus, although the lytic activity of PlyBt33-N was relatively low when compared with PlyBt33 (Figure 4e). To detect the lytic spectrum of PlyBt33, the lytic activity of purified PlyBt33 was tested against $B$. thuringiensis strains HD-73, HD-1, four $B$. thuringiensis isolates, B. subtilis, B. pumilus, $B$ cereus, $B$. anthracis, and the Gram-negative strains P. aeruginosa, Y. pseudotuberculosis, and E. coli.
PlyBt33 lysed all Bacillus strains tested, but not the Gram-negative strains. The lytic activity against $B$. thuringiensis was low, but was much higher against $B$. subtilis and B. pumilus (Figure 5a), which corresponded with previous reports [17,31]. Furthermore, PlyBt33 lysed $B$. cereus and $B$. anthracis with higher lytic activity.

The effects of $\mathrm{pH}$ and temperature on PlyBt33 lytic activity were investigated. Lytic activity against the tested strains was observed in the $\mathrm{pH}$ range of 7.0-12.0, with an optimal $\mathrm{pH}$ of 9.0 (Figure $5 \mathrm{~b}$ ). The optimum reaction temperature was $50^{\circ} \mathrm{C}$ (Figure $5 \mathrm{c}$ ), and lytic activity gradually decreased as temperature increased from $30-60^{\circ} \mathrm{C}$ (Figure $5 \mathrm{~d}$ ). Following treatments at $40^{\circ} \mathrm{C}$ and $60^{\circ} \mathrm{C}$ for $1 \mathrm{~h}$, lytic activity was reduced by $40 \%$ and $60 \%$, respectively.

\section{Cell wall binding activity of PlyBt33-IC}

According to previous reports, the C-termini of several characterized Gram-positive endolysins comprised one or several SH3 family cell wall binding domains $[11,14,30]$. Pfam analysis of PlyBt33 showed that the PlyBt33 C-terminus consisted of an Amidase02_C domain, which was present in several endolysins $[9,18]$. We aligned the PlyBt33 C-terminus with other characterized cell wall binding domains from Bacillus phage or prophage endolysins, and observed limited similarity. However, the highest similarity was found with the C-termini of PlyG, PlyL, PlyBa04, and PlyPH (Figure 1). Kikkawa et al. previously reported that amino acid residues L190 and Q199 of endolysin PlyG were critical for the cell wall binding activity of PlyG to B. anthracis [32]. Figure 1 showed that PlyBt33 and PlyG shared identical L190 residues but differred at amino acid 199.


Figure 4 Lytic activity assay of PlyBt33, PlyBt33-N, and PlyBt33-IC. (a), (b), (c), and (d). Filter papers were soaked in the crude extract suspended in 20 mM Tris-HCl (pH8.0) of PlyBt33 (a), PlyBt33-N (b), and PlyBt33-IC (c) from E. coli M15, and E. coli M15 containing pQE-30 (d), and placed onto the bacterial lawn of B. thuringiensis HD-73. (e) Lysis of viable cells using purified PlyBt33 and PlyBt33-N. Tests were performed in 20 $\mathrm{mM}$ Tris- $\mathrm{HCl}$ with a final protein concentration of $2 \mu \mathrm{M}$ at $37^{\circ} \mathrm{C}$. Crude extract of E. coli M15 containing pQE-30 was used as a control to treat $B$. thuringiensis strain HD-73. 
(a)

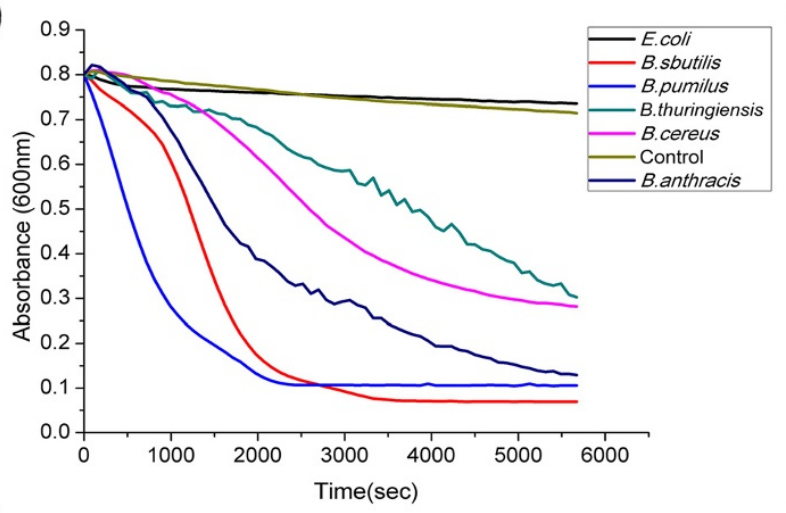

(c)



(b)

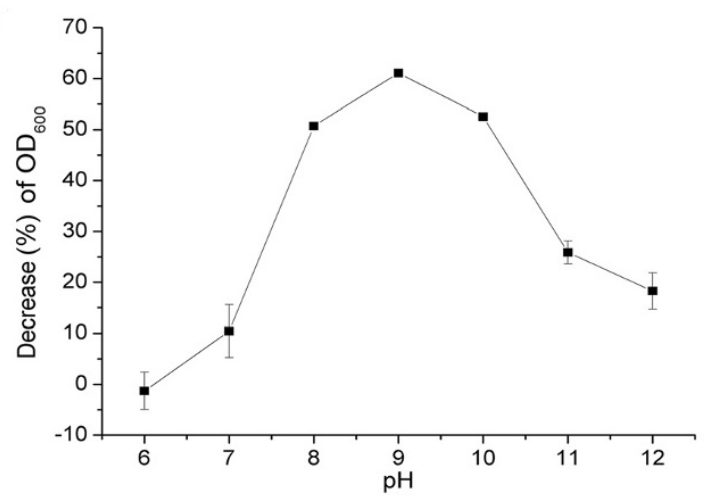

(d)

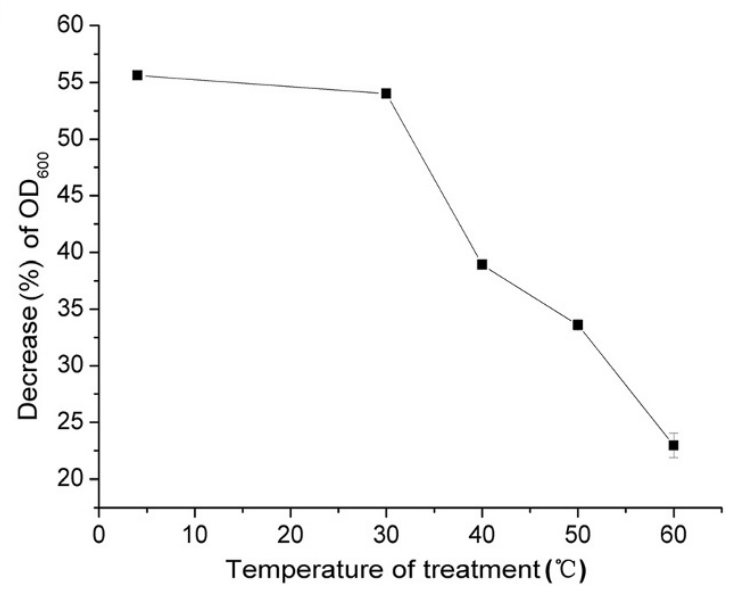

Figure 5 Characterization of the endolysin PlyBt33. (a) Lysis of viable cells from five different Bacillus species and one E. coli strain by PlyBt33. Tests were carried out with a final protein concentration of $2 \mu \mathrm{M}$ at $37^{\circ} \mathrm{C}$ in $20 \mathrm{mM} \mathrm{Tris-HCl}$ ( $\mathrm{pH} 8.0$ ). The initial OD 600 of each strain suspension was 0.8. Crude extract of E. coli M15 containing pQE-30 was used as a control to treat B. thuringiensis strain HD-73. (b) pH-dependent activity of PlyBt33. Tests were carried out with a final protein concentration of $2 \mu \mathrm{M}$ at $37^{\circ} \mathrm{C}$ in $20 \mathrm{mM}$ Tris at varying pH levels. (c) Temperature-dependent activity of PlyBt33. Tests were carried out with a final protein concentration of $2 \mu \mathrm{M}$ in $20 \mathrm{mM} \mathrm{Tris-} \mathrm{HCl}(\mathrm{pH} 8.0)$ at varying temperatures. (d) Temperature stability of PlyBt33. Proteins were first treated at different temperatures for $1 \mathrm{~h}$ and then the tests were carried out with a final protein concentration of $2 \mu \mathrm{M}$ at $37^{\circ} \mathrm{C}$ in $20 \mathrm{mM}$ Tris- $\mathrm{HCl}(\mathrm{pH} 8.0)$. In (b), (c), and (d), decrease of OD $600(\%)=(1-$ the absorbance of the bacterial suspension at the end of each treatment / the absorbance at the beginning of each treatment) $\times 100 \%$.

The PlyBt33 C-terminus was expressed, purified, and labeled with fluorescein isothiocyanate (FITC). After mixing FITC-PlyBt33-IC with the bacterial suspension for $5 \mathrm{~min}$, the cells were visualized under a fluorescence microscope, and binding between FITC-PlyBt33-IC and the surface of $B$. thuringiensis $\mathrm{HD}-73$ was apparent (Figure 6a). The binding ability assay was also repeated with a higher FITC-PlyBt33-IC concentration (0.05 mg/ml). At this concentration, homogenous binding of FITCPlyBt33-IC to the cell surface was observed (data not shown), in contrast to the random binding pattern seen at the lower concentration. FITC-labeled bovine serum albumin (BSA) showed no binding to HD-73 (Figure 6b), and the HD-73 cell suspensions used as a control showed no fluorescence (Figure 6c). FITC-PlyBt33-IC also bound to B. subtilis 168, while no binding was detected in E. coli (data not shown). The binding activity of PlyBt33-IC was consistent with its lytic specificity.

\section{Discussion}

In the present work, we expressed and determined the activity of endolysin PlyBt33 from B. thuringiensis phage BtCS33. The endolysin was found to be a putative $\mathrm{N}$-acetylmuramoyl-L-alanine amidase, and was composed of an N-terminal catalytic domain and a C-terminal cell wall binding domain. PlyBt33 maintained $40 \%$ of its lytic activity against bacterial cells following treatment at $60^{\circ} \mathrm{C}$ for $1 \mathrm{~h}$.

Though PlyBt33 exhibited a high sequence similarity (67\%) to endolysin $\mathrm{PlyPH}$, their characteristics were quite different. $\mathrm{PlyPH}$ was a $B$. anthracis putative prophage origin endolysin that could lyse B. anthracis and B. cereus, and had a broad optimal $\mathrm{pH}$ range $(\mathrm{pH} 4.0-10.5)$ [9]. By contrast, PlyBt33 exhibited lytic activity between $\mathrm{pH}$ 7.0-12.0, with an optimal $\mathrm{pH}$ of 9.0. The differences between the amino acid sequences of these two endolysins may cause differences in pI (putative pI 8.51 for 
(a)

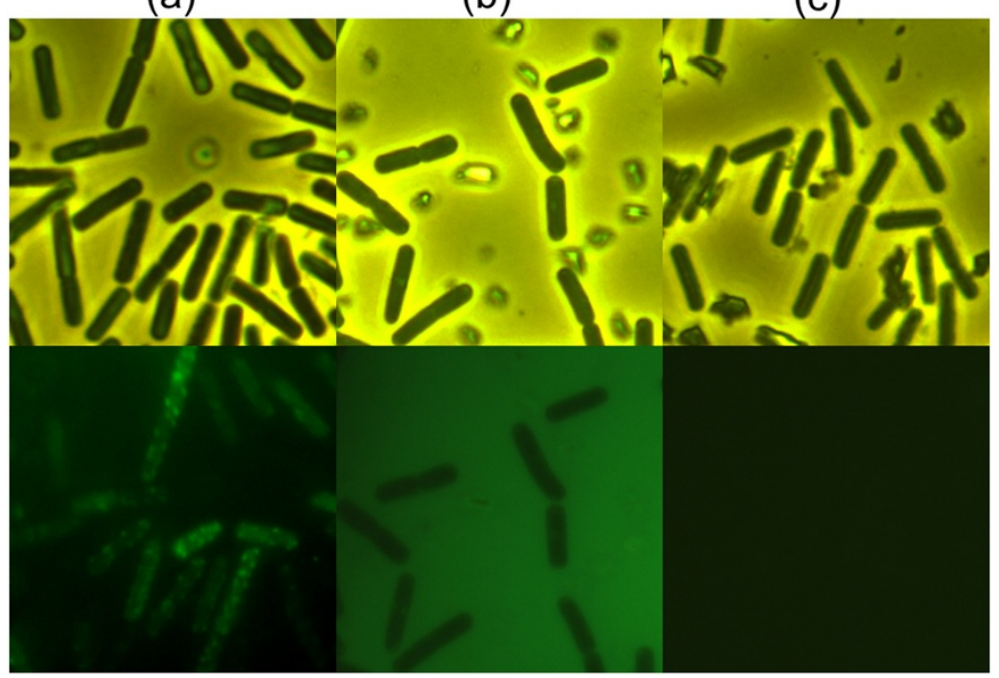

Figure 6 Binding ability of FITC-PlyBt33-IC to viable cells of $B$. thuringiensis HD-73, as observed by phase contrast (upper panels) and fluorescence (lower panels) microscopy. (a) Binding of FITC-PlyBt33-IC to the entire surface of HD-73; (b) No binding of FITC-BSA to HD-73 was observed; (c) HD-73 cell suspension with no protein was used as a control.

PlyBt33 and 6.15 for PlyPH) and different surface net charges. Low et al. [23] reported that the net charge of endolysin $\mathrm{PlyBa} 04$ influenced its lytic activity and specificity, which might explain the different $\mathrm{pH}$ ranges of these two endolysins. Moreover, the lytic spectrums of PlyBt33 and PlyPH were also different. PlyBt33 could hydrolyze all tested Bacillus strains from five different species, while PlyPH could only lyse $B$. anthracis and $B$. cereus. Alignments of the putative cell wall binding domains of PlyBt33 and PlyPH revealed a low similarity (about 20\%). According to previous reports, cell wall binding was essential in the host range determination of the endolysin $[12,32,33]$, and this might be the cause of the different target-specificities of PlyBt33 and $\mathrm{PlyPH}$. The same phenomenon was observed in endolysin PlyG (lytic specificity for B. anthracis and B. cereus) [18], which showed high similarity to PlyPH and low similarity to PlyBt33 at the putative cell wall binding region. Contrarily, B. anthracis endolysin PlyL showed low similarity to PlyBt33 at the putative cell wall binding region, but exhibited a relatively broad lytic spectrum. Both endolysins could lyse strains of $B$. anthracis, B. cereus, and B. subtilis [17]. We speculated that this was either because the different cell wall binding domains recognized the same cell wall epitope, or that there were various cell wall epitopes available for binding. Because of the low similarity of the PlyBt33 cell wall binding domain with others, we inferred that it might be a novel type of cell wall binding domain.

We observed random binding of the FITC labeled cell wall binding proteins with ligands on the cell surface (Figure 6a). The concentration used of the FITC labeled cell wall binding proteins $(0.0125 \mathrm{mg} / \mathrm{ml})$ was low, and as such only parts of the ligands were bound by the FITC labeled cell wall binding proteins. When a higher concentration $(0.05 \mathrm{mg} / \mathrm{ml})$ was used, the FITC labeled cell wall binding proteins bound uniformly to the cell surface (data not shown). These results suggested a homogenous distribution of ligands on the cell surface, which agrees with the findings of previous reports [12].

In previous reports, the lytic activity of PlyL increased after removing the C-terminal region [17], while the lytic activity of PlyG was reduced [18]. Though the similarity between the $\mathrm{N}$-terminal regions of PlyG and PlyL was high, they each exhibited distinct features. The similarity of PlyBt33 to PlyG and PlyL was low; therefore we decided to investigate the influence of the $\mathrm{C}$-terminus on the lytic activity of PlyBt33. In this study, when the C-terminus of PlyBt33 was removed, the lytic activity was reduced. We speculated that this was due to the $\mathrm{C}$-terminus assisting in the binding of PlyBt33 to the catalytic epitope on the cell wall of target bacteria, which benefits the catalysis of PlyBt33.

PlyBt33 had a relatively high thermostability, which, combined with its high lytic activity against $B$. cereus (a source of toxins in the food industry) [34,35], suggested that it had the potential to be an extremely useful antimicrobial agent in food production processes involving heat treatment [36]. PlyBt33 also exhibited a high lytic activity against $B$. anthracis, which indicated that it could be used in the treatment of anthrax [19]. 


\section{Conclusions}

The endolysin PlyBt33 was composed of two functional domains, the N-terminal catalytic domain and the $\mathrm{C}$-terminal cell wall binding domain. The $\mathrm{C}$-terminus of PlyBt33 might be a novel kind of cell wall binding domain. PlyBt33 lysed all tested Bacillus strains from five different species. Optimal conditions for PlyBt33 were $\mathrm{pH} 9.0$ and $50^{\circ} \mathrm{C}$, and PlyBt33 was also found to be relatively thermostable. These characteristics indicated that PlyBt33 might be an extremely useful antimicrobial agent in food production processes that involve heat treatment, and in the treatment of anthrax.

\section{Methods}

\section{Bacterial strains and cultures}

E. coli expression of the endolysin gene, respectively. B. thuringiensis strain HD-73 is the standard strain of B. thuringiensis subsp. kurstaki [37], while B. subtilis strain 168, obtained from Dr. Yuan Zhiming (Wuhan Institute of Virology, Chinese Academy of Sciences, Wuhan, China), is the most widely used model strain of B. subtilis [38]. B. anthracis CMCC63605 with the pXO1 plasmid eliminated was provided by Dr. Yuan Zhiming (Wuhan Institute of Virology, Chinese Academy of Sciences, Wuhan, China). B. thuringiensis strain CS-33 (CCTCC No. M202025) and phage BtCS33 (CGMCC7.61) were isolated by our laboratory. Other B. thuringiensis, B. cereus, and B. pumilus strains used in this study were collected and identified by our laboratory. Pseudomonas aeruginosa PAO1 (ATCC47085) and Yersinia pseudotuberculosis NaI (provided by Dr. Wang Yao, Wuhan Institute of Virology, Chinese Academy of Sciences, Wuhan, China) were used to test the lytic spectrum of the endolysin. All strains were grown in LB medium.

\section{Bioinformatic analysis of the putative endolysin gene of phage BtCS33}

Open reading frames (ORFs) of the phage BtCS33 genome (GenBank: JN191664) were predicted using FGENE SV software (http://linux1.softberry.com/berry.phtml?topic=virus\&group $=$ programs\&subgroup $=$ gfindv) and by visual inspection. The non-redundant protein database was searched using BLASTP [39] with the amino acid sequences of endolysins from BtCS33 and PlyBt33 as the query. ORF18 was predicted to encode the endolysin from BtCS33. Amino acid sequences of PlyBt33 and several known endolysins were aligned using ClustalW2 [40] and manually adjusted. Functional domains were searched against the Pfam database (http://pfam.sanger.ac.uk/ search) [41] and the CDD database (http://www.ncbi.nlm. nih.gov/cdd) [42].

\section{Plasmid construction and transformation}

DNA manipulations were performed according to standard protocols [43]. Phage BtCS33 genomic DNA was extracted as previously described [44] and used as a template to amplify the entire endolysin gene (ORF18, also known as plyBt33 and expressed as protein PlyBt33), the $\mathrm{N}$-terminal region gene (plyBt33-N, expressed as PlyBt33-N), and the internal and C-terminal region gene (plyBt33-IC, expressed as PlyBt33-IC). Primers and corresponding PCR products are listed in Table 1. Amplifications were performed in a Veriti 96-Well Thermal Cycler (Applied Biosystems, Foster City, CA) with an annealing temperature of $55^{\circ} \mathrm{C}$. PCR products were purified using a DNA extraction kit (Omega Bio-Tek, Norcross, GA) and inserted into the BamHI/SalI site of pQE-30 (Qiagen, Germany), which contains a His-tag for protein purification. Three recombinant plasmids were transformed into E. coli TG1, and three into E. coli M15. Positive transformants were selected and verified by DNA sequencing using a PRISM 3730 DNA analyzer (Applied Biosystems).

\section{Protein expression and purification}

Three transformants containing genes plyBt33, plyBt33$N$, and plyBt33-IC were cultured in LB broth containing $100 \mu \mathrm{g} / \mathrm{ml}$ ampicillin at $37^{\circ} \mathrm{C}$ with moderate rotation until cultures reached $\mathrm{OD}_{600}=0.4$. Cultures were then induced by the addition of $1 \mathrm{mM}$ IPTG at $16^{\circ} \mathrm{C}$ for $4 \mathrm{~h}$. Cells were collected by centrifugation at $10,000 \times g$ for $10 \mathrm{~min}$ and resuspended in $20 \mathrm{mM}$ Tris- $\mathrm{Cl}$ (pH 7.5). Following ultrasonication, debris was removed by centrifugation and the suspensions were harvested. Following filtration, proteins in the suspensions were purified using a Ni-nitrilotriacetic acid (NTA; Qiagen, German) column according to the manufacturer's instructions. Proteins PlyBt33 and PlyBt33-N were analyzed using 10\% SDS-PAGE, while protein PlyBt33-IC was analyzed using 15\% SDS-PAGE. Protein concentrations were calculated using the Bradford method [45]. Purified proteins were dialyzed against $20 \mathrm{mM}$ Tris- $\mathrm{HCl}(\mathrm{pH} 8.0)$ and stored at $-20^{\circ} \mathrm{C}$ until required.

\section{Lytic activity assay}

Crude protein extracts and purified proteins were assayed for lytic activity as described previously $[7,17]$. B. thuringiensis strains HD-73 and HD-1, four B. thuringiensis isolates, B. subtilis, B. pumilus, $B$ cereus, $B$. anthracis, and the Gram-negative strains $P$. aeruginosa, $Y$. pseudotuberculosis, and E. coli were used as indicator strains. Strains were grown to mid-exponential phase in LB broth, and then cells were harvested by centrifugation and resuspended in $20 \mathrm{mM}$ Tris- $\mathrm{HCl}$ buffer $(\mathrm{pH}$ 8.0). The Gram-negative strain cells were treated with $1 \mathrm{mM}$ EDTA in PBS to permeabilize the outer 
Table 1 Oligonucleotide primers pairs used in this study

\begin{tabular}{|c|c|c|c|}
\hline Primer pairs & Sequence $\left(5^{\prime}-3^{\prime}\right)$ & $\begin{array}{l}\text { PCR products } \\
\text { (Size) }\end{array}$ & $\begin{array}{l}\text { Predicted products/Size } \\
\text { (amino acid residues) }\end{array}$ \\
\hline plyBt33-F/ BamHI & GAGGATCC ${ }^{*}$ ATGGGTTACACTGTAGATATTTC & \multirow{2}{*}{$\begin{array}{l}\text { plyBt33 } \\
(816 \mathrm{bp})\end{array}$} & \multirow{2}{*}{$\begin{array}{l}\text { PlyBt33/33kDa } \\
\text { (amino acid residues 1-272) }\end{array}$} \\
\hline plyBt33-R/ Sall & GACGTCGACTTCTTTTGTATAAAAGTATTTAA & & \\
\hline plyBt33-F/ BamHI & GAGGATCCATGGGTTACACTGTAGATATTTC & \multirow{2}{*}{$\begin{array}{l}\text { plyBt33-N } \\
\text { (558bp) }\end{array}$} & \multirow{2}{*}{$\begin{array}{l}\text { PlyBt33-N/24kDa } \\
\text { (amino acid residues 1-186) }\end{array}$} \\
\hline plyBt33-N-R/ Sall & GACGTCGACTGTAAACCAATCTAACGACT & & \\
\hline plyBt33-IC-F/BamHI & GAGGATCCCTTGGATACACTTCAAAAAT & \multirow{2}{*}{$\begin{array}{l}\text { plyBt33-IC } \\
\text { (258bp) }\end{array}$} & \multirow{2}{*}{$\begin{array}{l}\text { PlyBt33-IC/11 kDa } \\
\text { (amino acid residues 187-272) }\end{array}$} \\
\hline plyBt33-R/ Sall & GACGTCGACTTCTTTTGTATAAAAGTATTTAA & & \\
\hline
\end{tabular}

${ }^{*}$ The characters underline represents the restriction enzymes digest sites.

membranes prior to testing their susceptibility to PlyBt33. For rapid screening of the lytic spectrum, the indicator strains were plated onto LB plates and crude lysate of expressed proteins was added to filter paper that was placed on the bacterial lawn. Plates were incubated at $30^{\circ} \mathrm{C}$ overnight. Additionally, purified proteins were added at a ratio of 1:9 to cell suspensions (initial $\left.\mathrm{OD}_{600}=0.8\right)$ and the absorbance at $\mathrm{OD}_{600}$ was monitored at $37^{\circ} \mathrm{C}$ for $1 \mathrm{~h}$ with a multimode reader (Bio-Tek Synergy HT, Winooski, VT). The crude extract of E. coli M15 containing plasmid pQE-30 was used as a control.

The optimal reaction $\mathrm{pH}$ of the endolysin was examined by adding dialyzed endolysins to cells of $B$. thuringiensis strain HD-73 resuspended in a series of

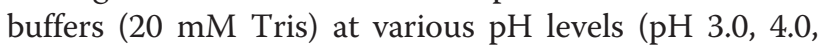
5.0, 6.0, 7.0, 8.0, 9.0, 10.0, 11.0, and 12.0), and the $\mathrm{OD}_{600}$ was monitored as described above. The optimal reaction temperature of the endolysin was tested in $20 \mathrm{mM}$ Tris- $\mathrm{HCl}(\mathrm{pH} 8.0)$ at temperatures of $10-80^{\circ} \mathrm{C}$ in $10^{\circ} \mathrm{C}$ increments, and the $\mathrm{OD}_{600}$ was again monitored. To analyze the endolysin thermostability, endolysins in 20 $\mathrm{mM}$ Tris- $\mathrm{HCl}(\mathrm{pH} 8.0)$ were first treated at different temperatures $\left(4^{\circ} \mathrm{C}, 30^{\circ} \mathrm{C}, 40^{\circ} \mathrm{C}, 50^{\circ} \mathrm{C}\right.$, and $\left.60^{\circ} \mathrm{C}\right)$ for $1 \mathrm{~h}$ and the lytic activity was tested as described above. All experiments were carried out in triplicate.

\section{Labeling and binding activity assay of PlyBt33-IC}

To test binding activity, purified PlyBt33-IC was labeled with FITC (Sigma-Aldrich, Saint Louis, MO) according to the manufacturer's instructions. Following purification, PlyBt33-IC protein was dialyzed four times against FITC reaction buffer (7.56 g NaHCO $3,1.06 \mathrm{~g} \mathrm{Na}_{2} \mathrm{CO}_{3}$, $7.36 \mathrm{~g} \mathrm{NaCl}$, with MilliQ water added to 11 and the $\mathrm{pH}$ adjusted to 9.0). FITC was dissolved in dimethyl sulfoxide to a concentration of $1 \mathrm{mg} / \mathrm{ml}$ and added into the PlyBt33-IC suspension at a ratio of $150 \mu \mathrm{g}$ FITC to $1 \mathrm{mg}$ PlyBt33-IC. Following $8 \mathrm{~h}$ incubation at $4^{\circ} \mathrm{C}$ in the dark, the reaction was stopped with $\mathrm{NH}_{4} \mathrm{Cl}$ at a final concentration of $50 \mathrm{mM}$ for $2 \mathrm{~h}$ at $4^{\circ} \mathrm{C}$ in the dark. The labeled protein was dialyzed against PBS $(8 \mathrm{~g} \mathrm{NaCl}, 0.2 \mathrm{~g} \mathrm{KCl}$, $3.49 \mathrm{~g} \mathrm{Na}_{2} \mathrm{HPO}_{4} .12 \mathrm{H}_{2} \mathrm{O}, 0.24 \mathrm{~g} \mathrm{KH}_{2} \mathrm{PO}_{4}$, with MilliQ water added to $1 \mathrm{l}$ and the $\mathrm{pH}$ adjusted to 7.4) several times until the dialysis liquid was colorless, and stored at $-20^{\circ} \mathrm{C}$ until required. BSA was also labeled as above and used as a control. FITC-labeled proteins were named FITC-PlyBt33-IC and FITC-BSA.

The specific binding activity of PlyBt33-IC to the cell wall was assayed as described previously with some modifications $[12,46]$. B. thuringiensis strain HD73 was grown to mid-exponential phase in LB broth $\left(\mathrm{OD}_{600}=0.8\right)$, and the cells were harvested by centrifugation $(10,000 \times g$ for $1 \mathrm{~min})$ and resuspended in a one-tenth volume of PBS-T (pH 7.4, 0.01\% Tween 20). FITC-labeled PlyBt33-IC was added to a $100 \mu \mathrm{l}$ cell suspension to a final concentration of $0.0125 \mathrm{mg} / \mathrm{ml}$ and incubated at $30^{\circ} \mathrm{C}$ for $5 \mathrm{~min}$. For fluorescence microscopy observation, the cells were harvested by centrifugation and washed twice with $500 \mu \mathrm{l}$ PBS-T buffer. The pellet was then resuspended in $50 \mu$ PBS-T. FITC-labeled BSA was used as a control. All cells were observed using an Olympus BX51 microscope.

\section{Competing interests}

The authors have no competing interests to declare.

Authors' contributions

YHY and QP conducted the protein analysis. YHY performed the bioinformatics analyses. MYG supervised the work. MYG and YHY designed the study and wrote the manuscript. All authors reviewed and approved the final version of the manuscript.

\section{Acknowledgments}

This study was supported by the National Natural Science Foundation of China (No.31170123), the National Project (2009ZX08009-056B), and the projects of the Chinese Academy of Sciences (KSCX2-EW-G-16).

Received: 13 July 2012 Accepted: 10 December 2012

Published: 19 December 2012

\section{References}

1. Hermoso JA, Garcia JL, Garcia P: Taking aim on bacterial pathogens: from phage therapy to enzybiotics. Curr Opin Microbiol 2007, 10(5):461-472.

2. Loessner MJ: Bacteriophage endolysins - current state of research and applications. Curr Opin Microbiol 2005, 8(4):480-487.

3. White R, Chiba S, Pang T, Dewey JS, Savva CG, Holzenburg A, Pogliano K, Young R: Holin triggering in real time. Proc Natl Acad Sci USA 2011, 108(2):798-803.

4. Loessner MJ, Wendlinger G, Scherer S: Heterogeneous Endolysins in Listeria-Monocytogenes Bacteriophages - a New Class of Enzymes and Evidence for Conserved Holin Genes within the Siphoviral Lysis Cassettes. Mol Microbiol 1995, 16(6):1231-1241. 
5. Fenton M, Ross RP, McAuliffe O, O'Mahony J, Coffey A: Characterization of the staphylococcal bacteriophage lysin CHAP(K). J Appl Microbio/ 2011, 111(4):1025-1035.

6. Gupta R, Prasad Y: P-27/HP Endolysin as Antibacterial Agent for Antibiotic Resistant Staphylococcus aureus of Human Infections. Curr Microbiol 2011, 63(1):39-45.

7. Nariya H, Miyata S, Tamai E, Sekiya H, Maki J, Okabe A: Identification and characterization of a putative endolysin encoded by episomal phage phiSM101 of Clostridium perfringens. Appl Microbiol Biot 2011, 90(6):1973-1979.

8. Schuch R, Nelson D, Fischetti VA: A bacteriolytic agent that detects and kills Bacillus anthracis. Nature 2002, 418(6900):884-889.

9. Yoong P, Schuch R, Nelson D, Fischetti VA: PlyPH, a bacteriolytic enzyme with a broad $\mathrm{pH}$ range of activity and lytic action against Bacillus anthracis. J Bacteriol 2006, 188(7):2711-2714

10. Nelson DC, Schmelcher M, Rodriguez-Rubio L, Klumpp J, Pritchard DG, Dong S, Donovan DM: Endolysins as antimicrobials. Adv Virus Res 2012 83:299-365

11. Porter CJ, Schuch R, Pelzek AJ, Buckle AM, McGowan S, Wilce MCJ, Rossjohn J, Russell R, Nelson D, Fischetti VA: The 1.6 A crystal structure of the catalytic domain of PlyB, a bacteriophage lysin active against Bacillus anthracis. J Mol Biol 2007, 366(2):540-550.

12. Loessner MJ, Kramer K, Ebel F, Scherer S: C-terminal domains of Listeria monocytogenes bacteriophage murein hydrolases determine specific recognition and high-affinity binding to bacterial cell wall carbohydrates. Mol Microbiol 2002, 44(2):335-349.

13. Nelson D, Schuch $R$, Chahales P, Zhu SW, Fischetti VA: PlyC: A multimeric bacteriophage lysin. Proc Natl Acad Sci USA 2006, 103(28):10765-10770.

14. Schmitz JE, Ossiprandi MC, Rumah KR, Fischetti VA: Lytic enzyme discovery through multigenomic sequence analysis in Clostridium perfringens. Appl Microbiol Biot 2011, 89(6):1783-1795.

15. Matthews BHM, Matthews BW: Extension to 2268 atoms of direct methods in the ab initio determination of the unknown structure of bacteriophage P22 lysozyme. Acta Crystallogr D 2006, 62:165-176.

16. Xu M, Arulandu A, Struck DK, Swanson S, Sacchettini JC, Young R: Disulfide isomerization after membrane release of its SAR domain activates P1 lysozyme. Science 2005, 307(5706):113-117.

17. Low LY, Yang C, Perego M, Osterman A, Liddington RC: Structure and lytic activity of a Bacillus anthracis prophage endolysin. J Biol Chem 2005 280(42):35433-35439.

18. Kikkawa HS, Ueda T, Suzuki S, Yasuda J: Characterization of the catalytic activity of the gamma-phage lysin, PlyG, specific for Bacillus anthracis. FEMS Microbiol Lett 2008, 286(2):236-240.

19. Vilas-Boas GT, Peruca APS, Arantes OMN: Biology and taxonomy of Bacillus cereus, Bacillus anthracis, and Bacillus thuringiensis. Can J Microbiol 2007, 53(6):673-687

20. Schnepf E, Crickmore N, Van Rie J, Lereclus D, Baum J, Feitelson J, Zeigler DR, Dean DH: Bacillus thuringiensis and its pesticidal crystal proteins. Microbiol Mol Biol R 1998, 62(3):775-+

21. Serizawa M, Sekizuka T, Okutani A, Banno S, Sata T, Inoue S, Kuroda M: Genomewide Screening for Novel Genetic Variations Associated with Ciprofloxacin Resistance in Bacillus anthracis. Antimicrob Agents Ch 2010, 54(7):2787-2792

22. Athamna A, Athamna M, Abu-Rashed N, Medlej B, Bast DJ, Rubinstein E: Selection of Bacillus anthracis isolates resistant to antibiotics. J Antimicrob Chemoth 2004, 54(2):424-428.

23. Low LY, Yang C, Perego M, Osterman A, Liddington R: Role of Net Charge on Catalytic Domain and Influence of Cell Wall Binding Domain on Bactericidal Activity, Specificity, and Host Range of Phage Lysins. J Biol Chem 2011, 286(39):34391-34403.

24. Lopez R, Garcia E, Garcia P, Garcia JL: The pneumococcal cell wall degrading enzymes: A modular design to create new lysins? Microbial Drug Resistance-Mechanisms Epidemiology and Disease 1997, 3(2):199-211.

25. Verheust C, Fornelos N, Mahillon J: The Bacillus thuringiensis phage GIL01 encodes two enzymes with peptidoglycan hydrolase activity. FEMS Microbiol Lett 2004, 237(2):289-295.

26. Yuan YH, Gao MY, Wu DD, Liu PM, Wu Y: Genome characteristics of a novel phage from Bacillus thuringiensis showing high similarity with phage from Bacillus cereus. PLoS One 2012, 7(5):e37557. doi:10.1371/journal.pone.00.7557.
27. Loessner MJ, Maier SK, DaubekPuza H, Wendlinger G, Scherer S: Three Bacillus cereus bacteriophage endolysins are unrelated but reveal high homology to cell wall hydrolases from different bacilli. J Bacterio/ 1997, 179(9):2845-2851.

28. Fouts DE, Rasko DA, Cer RZ, Jiang LX, Fedorova NB, Shvartsbeyn A, Vamathevan JJ, Tallon L, Althoff R, Arbogast TS: Sequencing Bacillus anthracis typing phages Gramma and Cherry reveals a common ancestry. J Bacterio/ 2006, 188(9):3402-3408.

29. Klumpp J, Calendar R, Loessner MJ: Complete Nucleotide Sequence and Molecular Characterization of Bacillus Phage TP21 and its Relatedness to Other Phages with the Same Name. Viruses-Basel 2010, 2(4):961-971.

30. Cheng $Q$, Fischetti VA: Mutagenesis of a bacteriophage lytic enzyme PlyGBS significantly increases its antibacterial activity against group B streptococci. Appl Microbiol Biot 2007, 74(6):1284-1291.

31. Briers $Y$, Volckaert $G$, Cornelissen A, Lagaert S, Michiels CW, Hertveldt $K$ Lavigne R: Muralytic activity and modular structure of the endolysins of Pseudomonas aeruginosa bacteriophages phi KZ and EL. Mol Microbiol 2007, 65(5):1334-1344.

32. Kikkawa H, Fujinami $Y$, Suzuki SI, Yasuda J: Identification of the amino acid residues critical for specific binding of the bacteriolytic enzyme of gamma-phage, PlyG, to Bacillus anthracis. Bioch Bioph Res Co 2007, 363(3):531-535

33. Bustamante N, Campillo NE, Garcia E, Gallego C, Pera B, Diakun GP, Saiz JL, Garcia P, Diaz JF, Menendez M: Cpl-7, a Lysozyme Encoded by a Pneumococcal Bacteriophage with a Novel Cell Wall-binding Motif. J Biol Chem 2010, 285(43):33184-33196.

34. Heyndrickx M, Scheldeman P: Bacilli associated with spoilage in dairy products and other food. In Applications and Systematics of Bacillus and Relatives. 2002:64-82

35. Granum PE, Lund T: Bacillus cereus and its food poisoning toxins. FEMS Microbiol Lett 1997, 157(2):223-228.

36. Schmelcher M, Waldherr F, Loessner MJ: Listeria bacteriophage peptidoglycan hydrolases feature high thermoresistance and reveal increased activity after divalent metal cation substitution. Appl Microbiol Biot 2012, 93(2):633-643.

37. Adang MJ, Staver MJ, Rocheleau TA, Leighton J, Barker RF, Thompson DV: Characterized Full-Length and Truncated Plasmid Clones of the Crystal Protein of Bacillus-Thuringiensis Subsp Kurstaki Hd-73 and Their Toxicity to Manduca-Sexta. Gene 1985, 36(3):289-300.

38. Srogl M: Some Factors Influencing Frequency of Transformation of Bacillus Subtilis 168. Folia Microbiol 1965, 10(3):202

39. Altschul SF, Madden TL, Schaffer AA, Zhang JH, Zhang Z, Miller W, Lipman DJ: Gapped BLAST and PSI-BLAST: a new generation of protein database search programs. Nucleic Acids Res 1997, 25(17):3389-3402.

40. Thompson JD, Higgins DG, Gibson TJ: Clustal-W:Improving the Sensitivity of Progressive Multiple Sequence Alignment through Sequence Weighting, Position-Specific Gap Penalties and Weight Matrix Choice. Nucleic Acids Res 1994, 22(22):4673-4680.

41. Bateman A, Coin L, Durbin R, Finn RD, Hollich V, Griffiths-Jones S, Khanna A, Marshall M, Moxon S, Sonnhammer ELL: The Pfam protein families database. Nucleic Acids Res 2004, 32:D138-D141.

42. Marchler-Bauer A, Lu SN, Anderson JB, Chitsaz F, Derbyshire MK, DeWeese-Scott C, Fong JH, Geer LY, Geer RC, Gonzales RC, et al: CDD: a Conserved Domain Database for the functional annotation of proteins. Nucleic Acids Res 2011, 39:D225-D229.

43. Sambrook J, Fritsch EF, Maniatis T: Molecular cloning. A laboratory manual. 3rd edition. Cold Spring Harbor: Cold spring Harbor laboratory Press; 2001.

44. Santos MA: An improved method for the small-scale preparation of bacteriophage DNA baded on phage precipitation by Zinz-Chloride. Nucleic Acids Res 1991, 19(19):5442-5442.

45. Schleicher E, Wieland OH: Evaluation of Bradford Method for Protein Determination in Body-Fluids. J Clin Chem Clin Biochem 1978, 16(9):533-534

46. Gerova M, Halgasova N, Ugorcakova J, Bukovska G: Endolysin of bacteriophage BFK20: evidence of a catalytic and a cell wall binding domain. FEMS Microbiol Lett 2011, 321(2):83-91.

doi:10.1186/1471-2180-12-297

Cite this article as: Yuan et al:: Characteristics of a broad lytic spectrum endolysin from phage BtCS33 of Bacillus thuringiensis. BMC Microbiology 2012 12:297. 